\section{A Competitive Market Analysis of the United States Shiitake Mushroom Marketplace}

\author{
Michael A. Gold ${ }^{1,2}$, Mihaela M. Cernusca ${ }^{1}$, and Larry D. Godsey ${ }^{1}$
}

ADDITIONAL INDEX wORDs. Lentinus edodes, Porter's five forces model, agroforestry, forest farming, log-grown mushrooms

SUMMARY. Shiitake mushrooms (Lentinus edodes) have many nutritional and medicinal benefits. The cultivation of log-grown shiitake mushrooms encourages forest farming and can be an opportunity for farmers interested in developing an additional enterprise. In 2006, the University of Missouri Center for Agroforestry conducted a nationwide survey of shiitake mushroom producers to analyze the U.S. shiitake mushroom industry by taking into consideration the forces that influence competition based on Porter's five forces model. Shiitake mushrooms are grown primarily as a side business, especially those produced exclusively outdoors. Indoor production on sawdust generates higher income than outdoor production on logs, but $\log$ production is more suitable for a small-scale operation in an agroforestry setting. Barriers to entry are created by relationships in the market, economies of scale, and the learning curve effect. Although there are a limited number of spawn suppliers in the market, they produce quality inoculum and maintain good relationships with shiitake mushroom producers. The majority of respondents sell their shiitake mushrooms locally. Gourmet restaurants, farmers markets, and on-farm outlets are the main markets for shiitake mushrooms. Trends in demand are increasing and prices are high. Shiitake mushrooms can be replaced with other common or gourmet mushroom types, but also have their own identity for numerous nutritional and medicinal properties. Competition for log-grown shiitake mushrooms arises from shiitake mushrooms produced on sawdust and from imports. To successfully survive in the market, firms create competitive advantages through quality, customer service, and consistent supply. Barriers to success in the shiitake mushroom business include demanding work requirements, the need for a serious commitment to produce and market shiitake mushrooms, a 1-year time lag between investment and a return on investment, and insufficient production and marketing information. Grower associations, universities, and state and federal agencies must join their efforts to fund and support shiitake mushroom research and industry development.

$\mathrm{T}$ his article presents the results of research conducted to describe the shiitake mushroom market. The research builds upon previously reported findings that shed light on specific agroforestry markets such as redcedar (Juniperus virginiana) and chestnuts (Castanea spp.; Gold et al., 2005, 2006). The objective of this study is to analyze the U.S. shiitake mushroom industry from the

This work was funded through the University of Missouri Center for Agroforestry under cooperative agreement AG-02100251 with the USDA-ARS Dale Bumpers, Small Farms Research Center, Boonville, AR.

The results presented are the sole responsibility of the principal investigators and/or MU and may not represent the policies or positions of the ARS

We thank Dr. Jim Chamberlain, Virginia Tech University, and Dr. Dan Cernusca, University of Missouri, for their review and insightful comments on an earlier version of this manuscript.

${ }^{1}$ Center for Agroforestry, University of Missouri, 203 ABNR Bldg., Columbia, MO 65211

${ }^{2}$ Corresponding author. E-mail: goldm@missouri. edu. producer's perspective by taking into consideration the forces that influence competition based on Porter's five forces model (PFFM; Porter, 1980).

Shiitake mushrooms are native to Asia and are grown in forests. They are one of the most popular cultivated varieties of specialty mushrooms. Shiitake mushrooms can be cultivated in two ways: in an outdoor setting on natural hardwood logs or in an environment-controlled building on logs or sawdust blocks. When they are cultivated outdoors, an agroforestry practice called forest farming is often used. In forest farming, high-value specialty crops are grown under the protection of a forest canopy that has been modified to provide the correct shade level. The advantages of outdoor production are a minimal capital investment and a better quality product. The outdoor production of shiitake mushrooms uses low-quality hardwoods, providing an additional income while creating opportunities for timber stand improvement. The disadvantages are seasonal production, dependence on weather, lower yields, longer delays until logs begin producing, and a heavier workload. The major advantages of producing shiitake mushrooms indoors on logs or sawdust are a constant market supply through year-round production, increased yields, and shorter production cycles. Disadvantages include higher initial investment costs, a specialized production process, and a lower quality product (Mycosource Inc., n.d.; Royse, 2001). Shiitake mushrooms are prized for their taste, nutritional value, and health benefits. They are low in calories, glucose, and sodium, and are high in potassium, phosphorus, copper, and zinc. Shiitake mushrooms contain lentinan, a polysaccharide that is being studied for its ability to increase immune system activity, reduce the potential for tumors, and lower blood pressure. Shiitake mushrooms help the body to produce interferon, an antiviral substance, as well as fight against asthma, colds, and flu. Shiitake mushrooms also contain eritadenine, which lowers blood cholesterol (Mattila et al., 2000; Mycosource Inc., n.d.).

The supply of shiitake mushrooms in the U.S. is increasing. The National Agricultural Statistics Service of the U.S. Department of Agriculture (USDA) provides statistics for shiitake mushrooms based on a survey distributed annually to mushroom growers across the United States. Based on the published data (USDA, 2004,2006 ), the number of shiitake mushroom growers with at least 200 logs in production or some commercial indoor growing area increased from 132 in $2001-02$, to 134 in

\begin{tabular}{llll}
\hline $\begin{array}{l}\text { Units } \\
\text { To convert U.S. to SI, } \\
\text { multiply by }\end{array}$ & U.S unit & SI unit & $\begin{array}{l}\text { To convert SI to U.S., } \\
\text { multiply by }\end{array}$ \\
\hline 0.0929 & $\mathrm{ft}^{2}$ & $\mathrm{~m}^{2}$ & 10.7639 \\
0.4536 & $\mathrm{lb}$ & $\mathrm{kg}$ & 2.2046 \\
1.6093 & mile(s) & $\mathrm{km}$ & 0.6214
\end{tabular}


2002-03, to 146 in 2003-04, to 164 in 2004-05, and to 176 in 2005-06. Compared with 2004-05, the production operation in 2005-06 measured in number of logs increased from 360,000 to $383,000 \operatorname{logs}$ for outdoor production and from 62,000 to $64,000 \operatorname{logs}$ for undercover and indoor production, whereas the area for growing media other than logs decreased from $1,585,000$ to $1,519,000 \mathrm{ft}^{2}$.

As shown in the following studies, demand for shiitake mushrooms is also growing in the retail, wholesale, foodservice, and consumer markets. Commercial producers of white button mushrooms [Agaricus bisporus (white strain)] have diversified into specialty mushrooms, creating a growing market for shiitake mushrooms (Beetz and Kustudia, 2004).

A study completed by the University of Alabama (Onianwa et al., 2000) analyzed the market potential for locally grown shiitake mushrooms at the retail-level in northern Alabama. Results revealed that shiitake mushrooms were the third most retailed mushroom in northern Alabama, ranking behind white button mushrooms and portabella mushrooms $[A$. bisporus (brown strain)], and before oyster mushrooms (Pleurotus spp.) and enoki mushrooms (Flammulina veluptipes). Fresh shiitake mushrooms were preferred for retail sales. Quality, freshness, and price were the most important attributes when sourcing shiitake mushrooms. Previous research performed in Ohio (Pickford, 1989) and in Florida (Degner and Williams, 1991) illustrated wholesalers' interest in shiitake mushrooms to supply the local restaurant industry.

The North Carolina Department of Agriculture and Consumer Services performed a survey (Augostini, 2002) to identify the trends in mushroom demand for the next 5 years. The target audience for this survey included retail and wholesale produce buyers from North Carolina, South Carolina, and Virginia. Based on the results, shiitake mushrooms were ranked third in terms of preference by buyers after white button and portabella mushrooms and ahead of oyster mushrooms and maitake mushrooms (Grifola frondosa). Increased demand for shiitake mushrooms was expected to outpace other types over the next 5 years. In general, $71 \%$ of respondents of the North Carolina survey described a growing demand for specialty mushrooms.

A detailed assessment of opportunities for fresh mushrooms in the foodservice channel was performed in a study sponsored by the Mushroom Council (Technomic, 2005). This study confirmed that shiitake mushrooms were the third most preferred species after white button mushrooms and portabella mushrooms. According to the results, shiitake mushrooms enjoy significant usage penetration $(21 \%$ of food service firms use shiitake mushrooms in their menus, 39\% use portabella mushrooms, and $67 \%$ use white button mushrooms). Over the past 2 years (from 2004 to 2006), net use of shiitake mushrooms in restaurants has increased by $17 \%$, and use of portabella mushrooms grew by $23 \%$. According to the study, the reason for growth is that restaurants are increasingly adding specialty mushrooms into their recipes to add variety and uniqueness, and consumers are increasingly adventurous, demanding unique flavors and textures that are provided by specialty mushrooms.

Research on the consumer side provided by the USDA's Economic Research Service revealed that per capita consumption of mushrooms (fresh and processed) increased from $3.69 \mathrm{lb}$ in 1990 to $4.02 \mathrm{lb}$ in 2006 , and per capita consumption of fresh mushrooms increased from $1.99 \mathrm{lb}$ in 1990 to $2.55 \mathrm{lb}$ in 2006 (USDA, 2007a). According to a study that used data from the USDA's Continuing Survey of Food Intake by Individuals, per capita consumption of mushrooms is higher in the western and midwestern United States and is weakest in the southern United States. Asian and non-Hispanic white consumers were the strongest consumers of mushrooms; per capita mushroom consumption was positively correlated with income; men and women between 20 and 39 years old were the leading mushroom consumers, representing about $32 \%$ of the population, yet consuming $43 \%$ of all mushrooms. According to the same study, specialty mushrooms, led by shiitake mushrooms and oyster mushrooms, have risen in popularity over the past decade (Lucier et al., 2003).
In a report prepared for the Mushroom Council by Arizona State University, United States fresh mushroom consumption is forecasted to increase at $1.9 \%$ per year, reaching $3.21 \mathrm{lb}$ per person by 2012 . Meanwhile, processed mushroom consumption is expected to remain constant at $1.65 \mathrm{lb}$ per person through 2012 (Patterson, 2003).

The University of Missouri Center for Agroforestry (UMCA) strives to establish new and profitable crops for Missouri land and forest owners to enhance and diversify farm income opportunities. In the forest farming area, UMCA is conducting research and demonstration projects to identify the types of mushrooms best suited for Missouri soils, as well as the best production techniques and management practices for cultivation of specialty mushrooms in agroforestry settings. Along with production research, encouraged by the favorable trends in supply and demand for shiitake mushrooms, UMCA is developing an understanding of the market at the national level. Detailed production and market information will help support widespread adoption of forest farming as an agroforestry practice. This study will provide market participants with useful decisionmaking information for developing marketing strategies and identifying potential for growth in this market.

\section{Materials and methods}

Shiitake mushroom producers throughout the United States were identified using information from the internet (e.g., keyword searches for businesses involved in all aspects of shiitake mushroom production and university websites that offered links to sources of specialty mushroom products) and a database was created. The questionnaire design and administration followed Dillman's (2000) tailored design method. A questionnaire combining yes/no and closed- and open-ended questions was developed to collect general information about the market participants (i.e., activities performed, specific questions about shiitake mushroom production, questions about utilization of brand name, advertising and publicity, size of production operation, degree of involvement in the production of shiitake mushrooms, and type of production) and information specific to each of 
the Porter's forces that influence the market. Some questions referred to shiitake mushrooms in general and some were specific for shiitake mushrooms grown on logs. The survey is available online on the UMCA website (UMCA, 2008).

The PFFM looks at five areas of competition that market participants face: barriers to entry, bargaining power of suppliers, bargaining power of buyers, threat of substitute products, and rivalry among existing firms (Porter 1980). The influence of governmental policies on the market was added to the PFFM. Porter's model focuses on the analysis not only of the actual situation (bargaining power of buyers and suppliers and rivalry among existing firms), but also on foreseeable developments (barriers to entry and threat of substitute products). By understanding the competitive forces within the shiitake mushroom industry, market opportunities and threats can be identified and successful strategies can be developed.

The questionnaire was tested on two growers and a researcher. Questionnaires were mailed to all businesses and individuals identified. To increase the sample size, letters were sent to various mushroom grower associations and publications asking them to notify shiitake mushroom growers about the upcoming survey and providing contact information for people that have not received a questionnaire and would like to participate in the survey. In addition, a question in each survey asked for names and contact information of other participants in the market. As a result, more names of potential respondents to the survey were generated. The newly identified individuals and businesses were added to the database and questionnaires were mailed to them.

After the first mailing, two postcard reminders and a subsequent mailing were sent to each individual on the list. Using SPSS (SPSS, Chicago), descriptive analysis was performed to analyze the data.

\section{Results}

Of 104 questionnaires mailed nationwide to valid addresses of shiitake mushroom producers, 36 useable surveys were received and analyzed $(36 \%$ response rate).
Responses came from 23 states, especially from the central and eastern regions of the United States.

\section{General information about respondents and the industry}

The PRODUCTION OPERATION. Farming of specialty mushrooms is often a source of supplemental income in the respondents' business. For $50 \%$ of the respondents, shiitake mushrooms represent less than half of their farming operation, whereas for $28 \%$ of respondents, shiitake mushrooms is the predominant product in their business. Information about the production operation such as production place, growing medium, and other types of specialty mushrooms grown by respondents in addition to shiitake mushrooms are presented in Table 1.

Concern about growing mushrooms without the use of pesticides and herbicides is very high among the respondents. Eighty-eight percent of respondents produce shiitake mushrooms organically and $40 \%$ certified their production under the USDA
National Organic Program or the Certified Naturally Grown program. Organic certification can help in marketing the products considering consumers' increased interest in chemical-free products (Mycosource, n.d.).

Revenue generated by SHIITAKE MUSHROOMS. Although more respondents grow shiitake mushrooms on logs, the highest production volume has been obtained from sawdust-grown shiitake mushrooms. Respondents reported their 2005 production on logs ranging from 50 to $7000 \mathrm{lb}$ and production on sawdust between 100 and $370,000 \mathrm{lb}$. Respondents with exclusively outdoor production reported gross annual sales under $\$ 25,000$. Returns up to $\$ 100,000$ were obtained by respondents that extended the log-grown outdoor operation with indoor production on logs or supplemented the log-grown production with indoor production on artificial substrates. Respondents that reported gross sales higher than $\$ 100,000$ annually produced shiitake

Table 1. Information about the production operation (i.e., production place and medium, type of spawn used, type of wood used and other species of specialty mushrooms grown besides shiitake mushrooms) of participants in a nationwide survey of U.S. shiitake mushroom producers.

\begin{tabular}{lc}
\hline Information about the production operation & $\begin{array}{c}\text { Proportion of } \\
\text { respondents (\%) }\end{array}$ \\
\hline Production place and medium & 42 \\
Grow shiitake mushrooms outdoors, on logs & 14 \\
Grow shiitake mushrooms outdoors and indoors, on logs & \\
Grow shiitake mushrooms outdoors and indoors, & 14 \\
$\quad$ on logs and sawdust & 30 \\
Grow shiitake mushrooms indoors, on sawdust & \\
Type of spawn used & 67 \\
Sawdust & 33 \\
Grain spawn & 19 \\
Dowel spawn & 6 \\
Thimble spawn & 3 \\
Stick spawn & \\
Type of wood used & 47 \\
Oak (Quercus spp.) & 22 \\
Maple (Acer spp.) & 8 \\
Sweetgum (Liquidambar styraciflua) & 20 \\
Others & \\
Other species of mushrooms grown by respondents & \\
Oyster & 58 \\
Maitake & 25 \\
Reishi (Ganoderma lucidum) & 19 \\
Pom-pom (Hericium americanum) & 19 \\
Stropharia (Stropharia rugosoannulata) & 11 \\
\hline
\end{tabular}

${ }^{2}$ Percentages do not add to 100 because respondents had the option to select more than one choice. yercentages do not add to the percentage of respondents that grow shiitake mushrooms on logs (69\%) because respondents had the option to list more than one type of wood. 
mushrooms exclusively indoors on sawdust substrate.

LONGEVITY IN SHIITAKE MUSHROOM PRODUCTION. A number of shiitake mushroom growers $(40 \%)$ are new in the business (less than 5 years), whereas one-quarter of the respondents began shiitake mushroom production 11 to 20 years ago, with the smallest group (17\%) producing for 20 years or longer.

Products sold. Shiitake mushroom growers are involved in various market-related activities (Fig. 1). Shiitake mushrooms grown outdoors are a seasonal product. Some of the respondents that built indoor facilities or used artificial substrate to produce shiitake mushrooms (47\% of respondents) are able to sell fresh shiitake mushrooms year round, and the others sell on a seasonal basis.

START-UP costs. According to the respondents, the costs to establish a shiitake mushroom business are not high. Seventy-two percent of respondents financed their business entirely from personal sources. The remaining $28 \%$ supplemented personal sources with bank loans, partners' finances, and grants. Respondents mentioned low start-up costs as an incentive to start a shiitake mushroom ple without the necessary capital, the lack of funds can be an obstacle to business establishment. In addition to initial start-up costs, labor costs, time, and resources are other considerations to take into account when establishing a shiitake mushroom business. business, but also noted that for peo-

BRANDING. More than half of respondents $(58 \%)$ recognize the importance of developing a brand name. Respondents created a brand name to build trust and relationships $(58 \%)$, encourage repeated purchase $(58 \%)$, increase awareness of their products $(50 \%)$, and stimulate word of mouth advertising (50\%). Other reasons for creating a brand name mentioned by respondents are the fact that a brand can be used to effectively communicate the local and organic message and can help sell a family of products. The more respondents added value to their product, from selling fresh shiitake mushrooms in bulk to selling value-added products, the higher the percentage that sell under a brand name (i.e., $73 \%$ of respondents that sell value-added products sell under a brand name compared with $55 \%$ of those who sell fresh shiitake mushrooms in bulk). A higher percentage of respondents that grow shiitake mushrooms on sawdust (75\%) sell under a brand name compared with those who grow on logs $(54 \%)$. More respondents that sell to an upscale store $(89 \%)$, online $(80 \%)$, or wholesale $(78 \%)$ developed a brand name compared with respondents that sell to restaurants $(56 \%)$ or farmers markets $(54 \%)$.

Overall, however, $42 \%$ of respondents choose not to develop a brand name because the volume they sell is too small or they address a local, direct, and loyal market that recognizes the quality of the products without the need of a brand name.

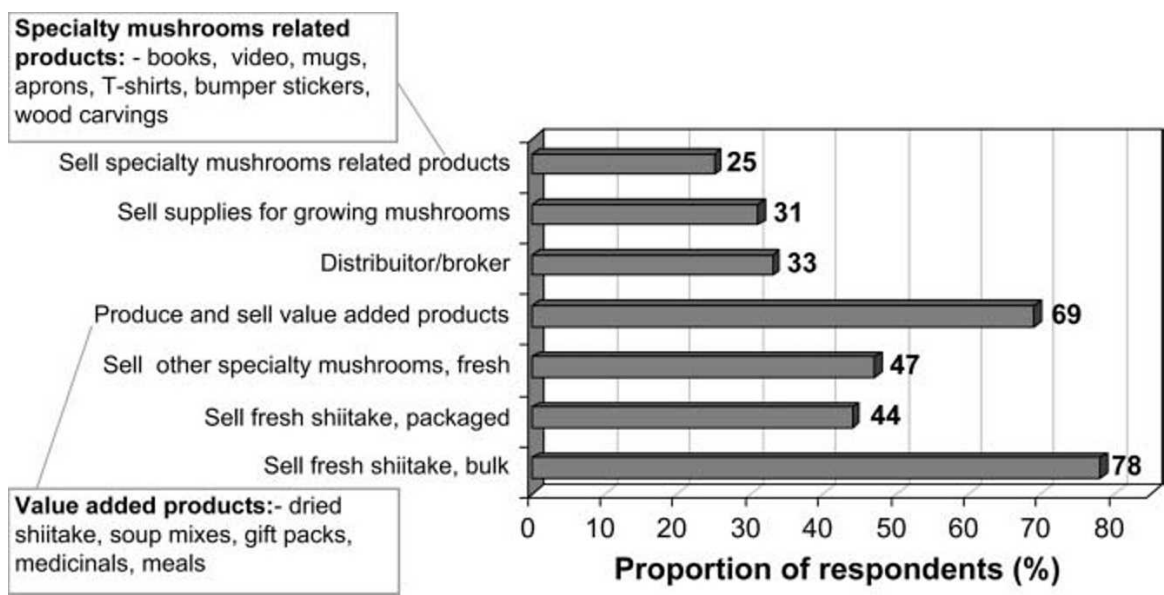

Fig. 1. Range of economic activities performed by participants in a nationwide survey of U.S. shiitake mushroom producers and the proportion of respondents involved in each activity $(N=36)$. Percentages do not add to 100 because respondents had the option to select more than one choice.
Twenty-five percent of respondents consider the possibility of creating a brand name in the future, whereas $17 \%$ definitely do not consider it necessary.

Marketing communication. Information can be transmitted to actual and potential customers through websites, paid advertising, publicity, and direct marketing. Marketing communication is a tool used by producers to build bridges to customers and channel partners, and to create and strengthen relationships. Thirty-six percent of respondents use a website to increase awareness about the products and services offered.

Fifty-seven percent of respondents use different advertising methods to increase awareness about their products (Table 2 ). The reasons mentioned for not advertising were greater demand than supply, and a small or beginning production. Nineteen percent of respondents do not plan to advertise in the future, $33 \%$ plan to advertise in the future, and $22 \%$ are not sure.

Publicity is used more often than advertising to increase awareness toward shiitake mushroom products (i.e., $83 \%$ use a form of publicity compared with $57 \%$ that use advertising) to raise awareness, inform, and educate consumers (Table 2). This communication method is more cost effective because it uses nonpaid media coverage of the firm and its products.

Critical resources for a SUCCESSFUL SHIITAKE MUSHROOM BUsIness. Production skills and production information were considered by respondents as the most critical resources for a successful shiitake mushroom business. Production skills and knowledge are necessary and are acquired in time through practical experience. Market knowledge, tools and equipment, and business skills were the next important critical resources declared by respondents. Other resources mentioned that contribute to the success of a shiitake mushroom business were labor availability and financial resources (Fig. 2).

WHAT ATTRACTED THE RESPONDENTS TO PRODUCE SHIITAKE MUSHROOMs. Respondents to the market research survey consider shiitake mushrooms a valuable crop because of its uniqueness and 
Table 2. Marketing communication methods used by participants in a nationwide survey of U.S. shiitake mushroom producers and proportion of respondents that use each method. Percentages do not add to 100 because respondents had the option to select more than one choice.

\begin{tabular}{lc}
\hline Marketing communication methods & $\begin{array}{c}\text { Proportion of } \\
\text { respondents (\%) }\end{array}$ \\
\hline Advertising & 19 \\
Newspapers & 19 \\
Magazines & 17 \\
Flyers & 17 \\
Catalogs & 8 \\
Radio & 6 \\
Television & 3 \\
Billboards & 17 \\
Others (big signs on trucks, advertising with health food & 50 \\
$\quad$ stores, and eBay) & 47 \\
Publicity & 33 \\
Free samples & 28 \\
Festivals and fairs & 8 \\
Collaborate with charities & 47 \\
Sponsor community events & \\
News releases & \\
Others (organize workshops, give talks and lectures, organize & \\
farm tours, participate in farmers markets, collaborate with & \\
local Community Supported Agriculture (CSA) groups, & \\
and word of mouth) & \\
\hline
\end{tabular}

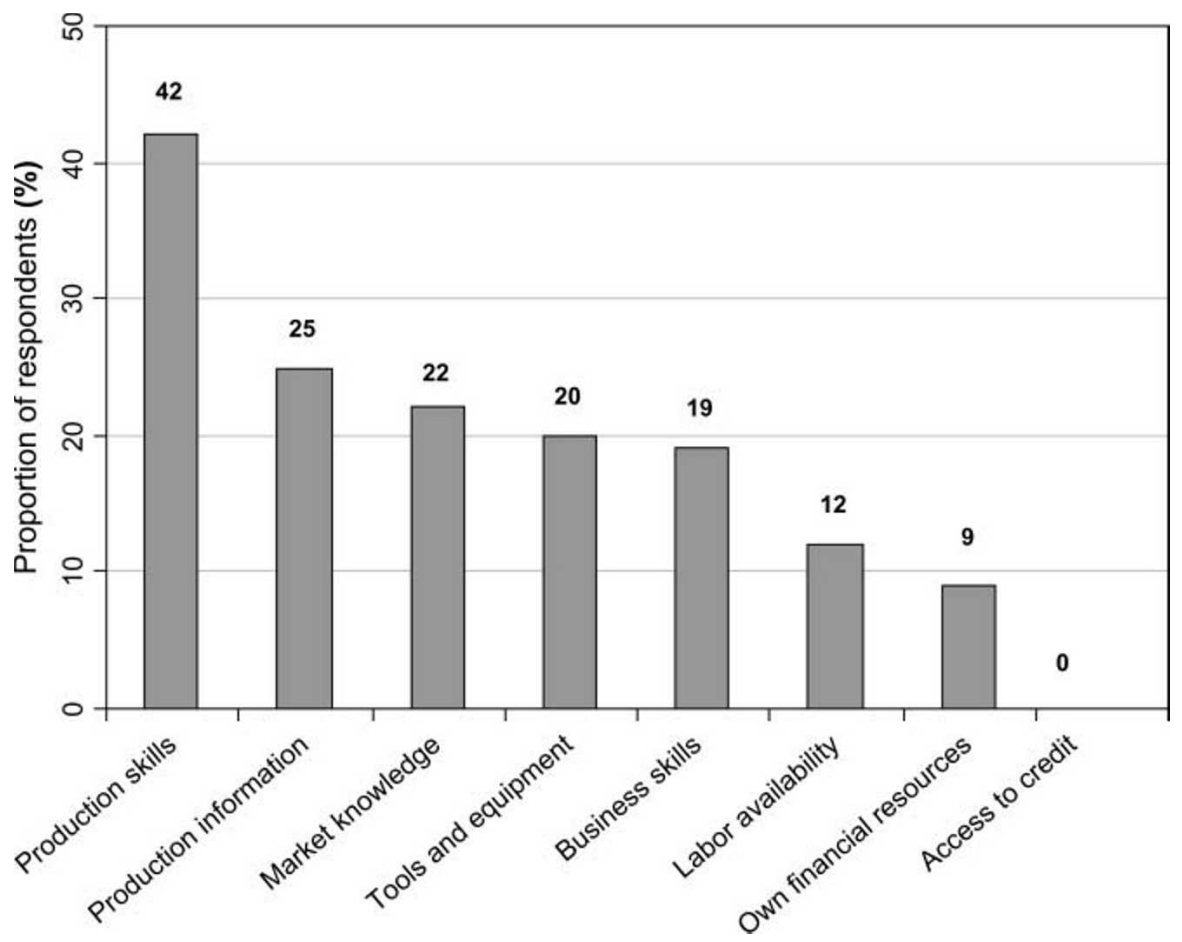

Fig. 2. Critical resources needed for a shiitake mushroom production business as identified by participants in a nationwide survey of U.S. shiitake mushroom producers $(\mathrm{N}=36)$. Values represent proportion of respondents that ranked the critical resources 1 or 2 on a scale of 1 to 5 ( 1 being the most important and 5 the least important).

popularity for taste, and nutritional and medicinal properties. Another reason for shiitake mushrooms' value is the sustainable impact on the environment through the production of shiitake mushrooms on natural logs. Respondents were motivated to produce shiitake mushrooms when resources such as logs, spawn, water, and proper microclimate were available and when information and training were easily accessible. The production of shiitake mushrooms is considered a potential source of profit by itself or in addition to a larger farming operation because of low start-up costs and the existence of potential markets (especially restaurants and farmers markets). Some respondents were motivated to produce shiitake mushrooms by their personal love for and interest in mushrooms. Promotion by state agencies and the information provided by books and magazines persuaded other respondents to start a shiitake mushroom business.

What KeEPS OTHER PEOPLE FROM STARTING SHIITAKE MUSHROOM PRODUCTION. According to the respondents, barriers to success in the shiitake mushroom business include the fact that it requires hard work and a serious commitment to produce and market shiitake mushrooms, the 1year time lag to obtain a return on investment, the lack of start-up funds, and insufficient production and marketing information. Respondents mentioned the long hours and dedication necessary to produce and market shiitake mushrooms. They considered shiitake mushroom production labor intensive. More than half of respondents (55\%) hire people to help with farm work. Twenty-eight percent hire full-time help (from 1 to 24 people), $25 \%$ hire part time (from 1 to 6 people), and $31 \%$ hire seasonal help (from 1 to 15) for administrative duties, laboratory work, production, packing, and delivery. A concern expressed by the respondents was the difficulty in finding local workers willing to work at competitive wages.

Compared with vegetable farming, growing shiitake mushrooms requires at least 1 year from inoculation to harvest. This issue can discourage people from starting a business according to some of the respondents. In addition, some respondents stated that the income is not high enough related to the amount of time invested. Seventeen percent of respondents indicated that it took about 2 years to become profitable, 22\% took between 2 and 4 years, and $11 \%$ were profitable after 4 years or more. Seventeen percent of respondents that have been in 
business for longer than 2 years indicated that they are not yet profitable. The lack of availability of funds and other resources may deter some people from starting a shiitake mushroom business.

Some people are prevented from starting a shiitake mushroom business because of lack of information about funding sources, production, and marketing. Most information about how to grow shiitake mushrooms is obtained by our respondents from suppliers (56\%) and other growers (53\%). Workshops (33\%), university researchers $(31 \%)$, the internet $(31 \%)$, books (25\%), grower associations (22\%), magazines (19\%), and cooperative extension services (17\%) are other sources of information mentioned by respondents.

The fear of competition from sawdust-grown shiitake mushrooms and foreign producers were mentioned as other factors that may discourage some individuals from starting a shiitake mushroom business.

\section{Information about the market}

Suppliers. There are a limited number of suppliers of spawn for the shiitake mushroom industry. Field and Forest Company was mentioned as the primary spawn supplier by most respondents (42\%), followed by Northwest Mycological in Oregon, Fungi Perfecti in Washington State, North Carolina A\&T, and Mushroom People in Tennessee. The quality of spawn available through supply channels is considered to be good by $64 \%$ of respondents, readily available by $53 \%$, and stable by $44 \%$. Unique to the niche markets is the lack of formal contracts between producers and suppliers. Less than $8 \%$ of respondents have formal contracts with suppliers of spawn, growing medium, tools, or packaging.

MARKeT OUTLETS AND PRICES FOR FRESH SHITTAKE MUSHROOMS. The majority of respondents (81\%) sell their shiitake mushrooms locally (within 75 miles radius), 39\% sell regionally (between 75 and 200 miles radius), $14 \%$ sell nationally, and $3 \%$ internationally.

Gourmet restaurants (75\%), farmers markets $(69 \%)$, and on-farm outlets $(61 \%)$ are the main marketing venues for the respondents. Less-used market outlets include health food stores $(39 \%)$, upscale stores $(25 \%)$, wholesalers (25\%), and distributors $(25 \%)$. In spite of the overwhelming popularity of the internet as a sales tool, only $14 \%$ of respondents have internet sales (Fig. 3).

For our survey sample, prices varied considerably: fresh shiitake mushrooms brought $\$ 5$ to $\$ 7$ per pound wholesale for log-grown shiitake mushrooms. Customers at farmers markets were paying $\$ 6$ to $\$ 16$ per pound of fresh, log-grown shiitake mushrooms, and chefs were paying $\$ 5.50$ to $\$ 16$ per pound to include log-grown shiitake mushrooms on their menus. Retail stores paid $\$ 5.50$ to $\$ 11$ per pound of fresh shiitake mushrooms. Some respondents sold shiitake mushrooms onfarm for $\$ 5$ to $\$ 16$ per pound (Fig. 4 ).

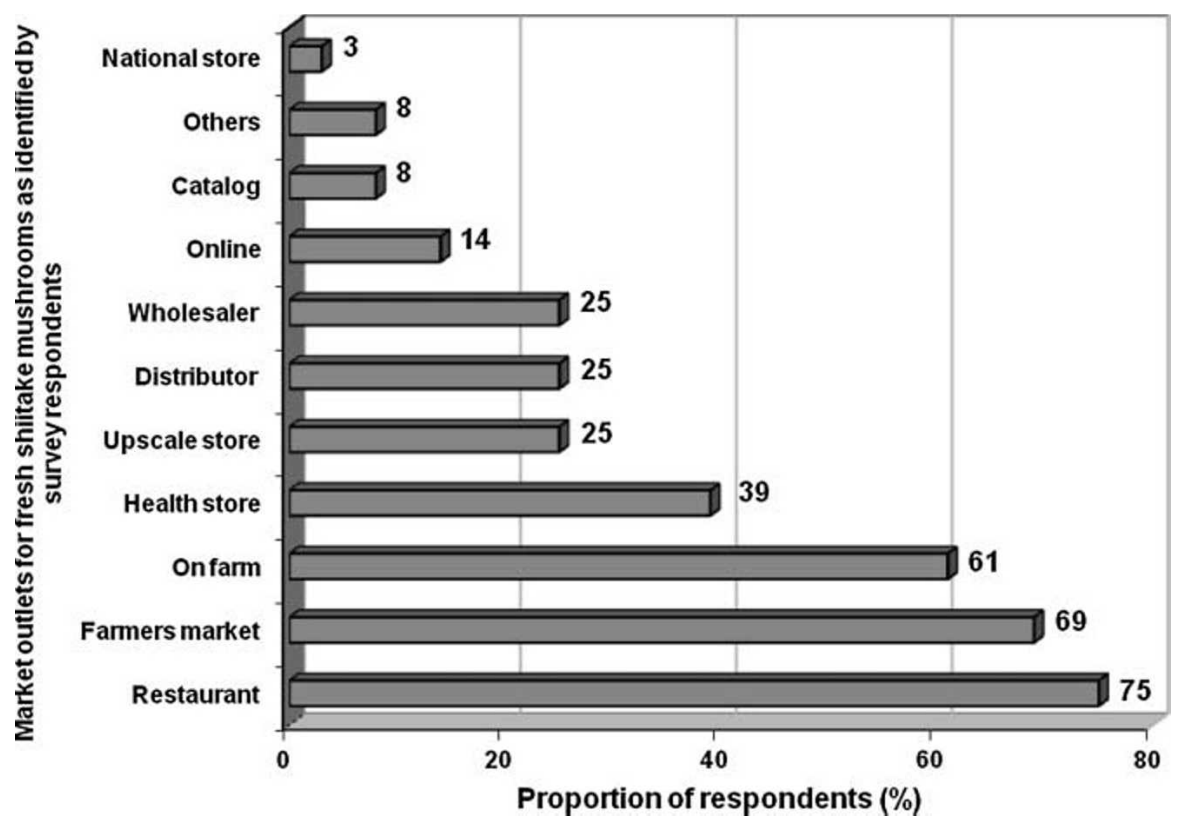

Fig. 3. Outlets for fresh shiitake mushroom sales used by participants in a nationwide survey of U.S. shiitake mushroom producers and the proportion of respondents that sell in each outlet $(N=36)$. Percentages do not add to 100 because respondents had the option to select more than one choice.

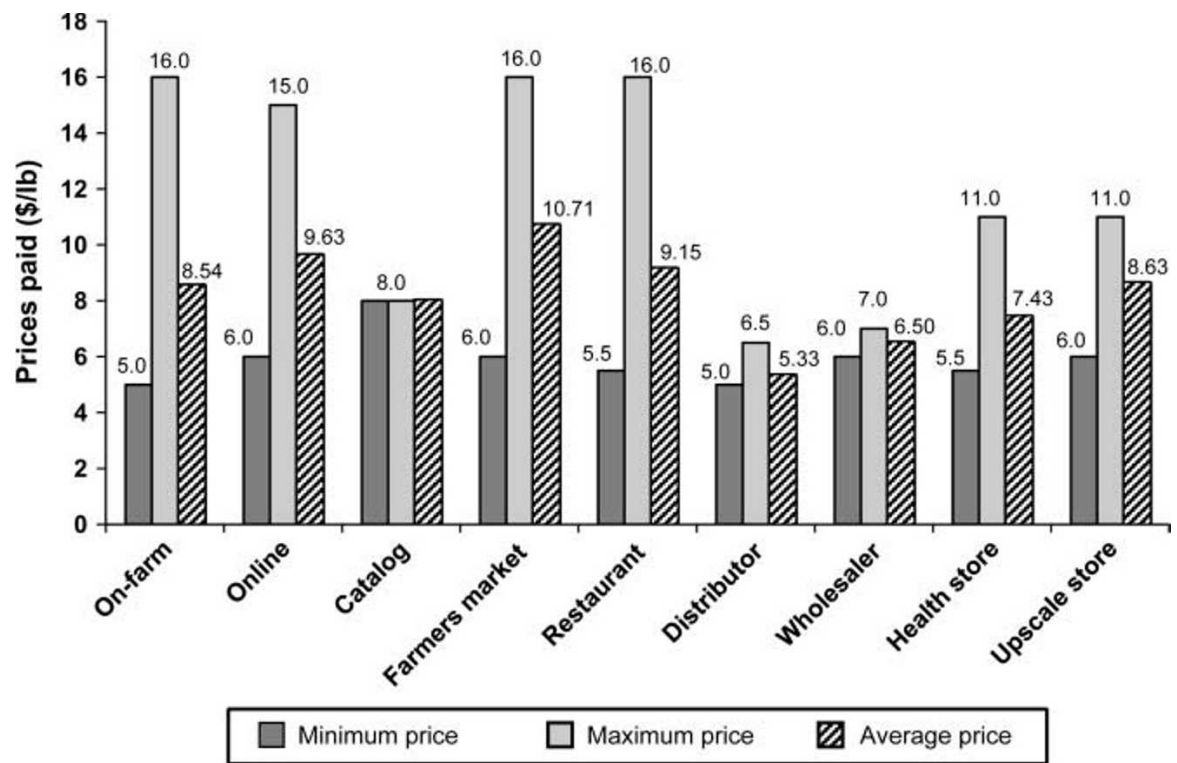

Fig. 4. Maximum, minimum, and average prices paid by different buyers for fresh $\log$-grown shiitake mushrooms as identified by participants in a nationwide survey of U.S. shiitake mushroom producers $(\mathrm{N}=36) ; \$ 1.00 / 1 \mathrm{~b}=\$ 2.2046 / \mathrm{kg}$. 
At the farm gate, farmers market, restaurant, distributor, wholesale, and upscale store levels, the average price received for log-grown shiitake mushrooms was slightly higher than the one received for sawdust-grown shiitake mushrooms. Prices differed the most at the wholesale level (\$4.40/lb for sawdust compared with a $\$ 6.50 / \mathrm{lb}$ average price for $\log$ grown shiitake mushrooms). For this particular sample, sawdust-grown shiitake mushrooms received higher prices when sold online or in health food stores compared with log-grown shiitake mushrooms (Fig. 5).

According to survey respondents, the price for fresh shiitake mushrooms remained stable or increased up to $25 \%$ over the past 5 years. The same trend is expected for the next 5 years.

Mushrooms are perishable. To successfully market them, producers need to ensure that quality remains high through the supply channel. Respondents indicated that care should be provided to insure quality before delivery (refrigerate, deliver fresh, grade carefully, and use customized boxes). In addition, personal

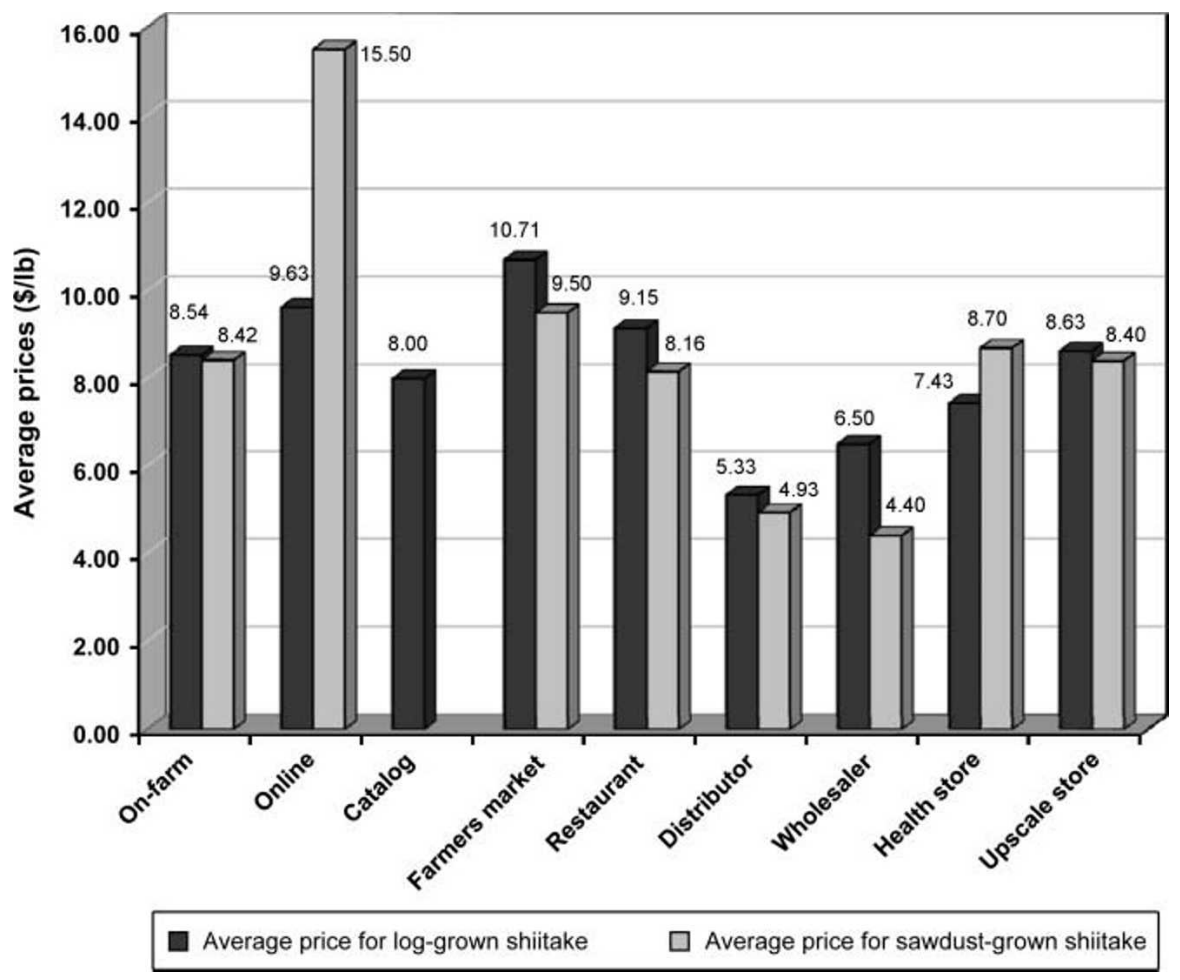

Fig. 5. Average prices paid by different buyers for log-grown shiitake mushrooms compared with average prices for sawdust-grown shiitake mushrooms as reported by participants in a nationwide survey of U.S. shiitake mushroom producers $(\mathrm{N}=36) ; \$ 1.00 / \mathrm{lb}=\$ 2.2046 / \mathrm{kg}$.

delivery or assurance that the delivery chain will be able to maintain freshness and high quality standards are necessary. Continuous communication and education are required along the process to ensure quality delivery. A large majority of respondents $(81 \%)$ deliver direct to market, $22 \%$ use shipping companies, $14 \%$ use refrigerated freight, and for $14 \%$, the buyer is responsible for pick up.

Trends In DEMAND. Based on the survey results, some respondents $(39 \%)$ noted an increase in demand during the past 5 years, and $11 \%$ stated that demand for fresh loggrown shiitake mushrooms remained stable during the past 5 years.

Roughly one-third of the respondents felt that current demand for fresh log-grown shiitake mushrooms is steady $(36 \%), 19 \%$ think that demand is strong, and $6 \%$ that demand is weak. Aside from "I don't know" responses, 29\% believe that current demand is in excess of supply, $14 \%$ indicate that it is equal to supply, and $14 \%$ that it is below supply. Fortyseven percent of respondents stated that demand for fresh log-grown shiitake mushrooms will increase over

Hartecthology $\cdot$ July-September $200818(3)$ the next 5 years and $11 \%$ indicated that demand will remain stable. Importantly, no respondent believed that demand will decrease over the next 5 years. Fifty-six percent of respondents were able to maintain a steady supply of shiitake mushrooms from their own production $(47 \%)$ or by brokering for other growers (17\%).

The trend for value-added products is similar to the trend for fresh shiitake mushrooms. Thirty-one percent of respondents think that demand increased during the last 5 years, $11 \%$ that demand remained stable, and $6 \%$ that demand decreased. Now, demand for valueadded shiitake mushroom products is considered stable by $39 \%$ of respondents, weak by $11 \%$, and strong by $8 \%$ of respondents. Fifty-five percent of respondents do not know what will happen with demand for value-added shiitake mushroom products over the next 5 years, but $42 \%$ believe that demand will increase.

Substitutes for shittake MUSHROOMs. In general, the common white button mushroom and other mushrooms such as portabella can be substituted for shiitake mushrooms at a lower price and higher availability. Oyster mushrooms were mentioned as a same price, quality, and availability substitute, and chanterelle mushrooms, maitake mushrooms, morels (Morchella spp.), porcini mushrooms (Boletus edulis), or truffles (Tuber spp.) are potential higher-priced substitutes that are less available than shiitake mushrooms.

COMPETITORS AND COMPETITIVE ADVANTAges. Respondents considered the shiitake mushroom industry to be moderately competitive (28\%) or noncompetitive $(22 \%)$. Over the past 5 years, the number of shiitake mushroom farms remained stable according to $30 \%$ of respondents, increased for $17 \%$, and decreased for $17 \%$. Twenty-two percent of respondents are the only producer of shiitake mushrooms in their area, 36\% share the area with one to three other farms, and $23 \%$ have more than four potential competitors in their area. Over the next 5 years, the number of shiitake mushroom farms is expected to remain stable according to $28 \%$ of respondents, increase $(28 \%)$, or decrease $(6 \%)$.

Quality $(75 \%)$, customer service (47\%), and consistent supply (33\%) 
are the most important competitive advantages mentioned by respondents. Market knowledge (25\%), resources $(19 \%)$, and skills $(17 \%)$ are next followed by quantity (11\%) and price $(6 \%)$. Some respondents mentioned locally grown and organic as competitive advantages.

\section{Discussion}

\section{Analysis of the forces that drive competition in the shiitake mushroom market}

The survey was designed to provide information about the forces that drive competition in the shiitake mushroom market. The PFFM served as a framework for examining the competitive environment. The results of the survey will be discussed for each of the Porter's five forces plus the impacts of governmental policy. A descriptive representation of the forces and their influence on the shiitake mushroom market has been developed (Fig. 6).

BARRIERS TO ENTRY. Barriers to entry inhibit new firms from entering the market, maintaining a higher level of profit for those already in the industry. High capital requirements, brand identity and advertising expenditures, access to distribution channels, and economies of scale are some of the most common characteristics that can create a threat for new

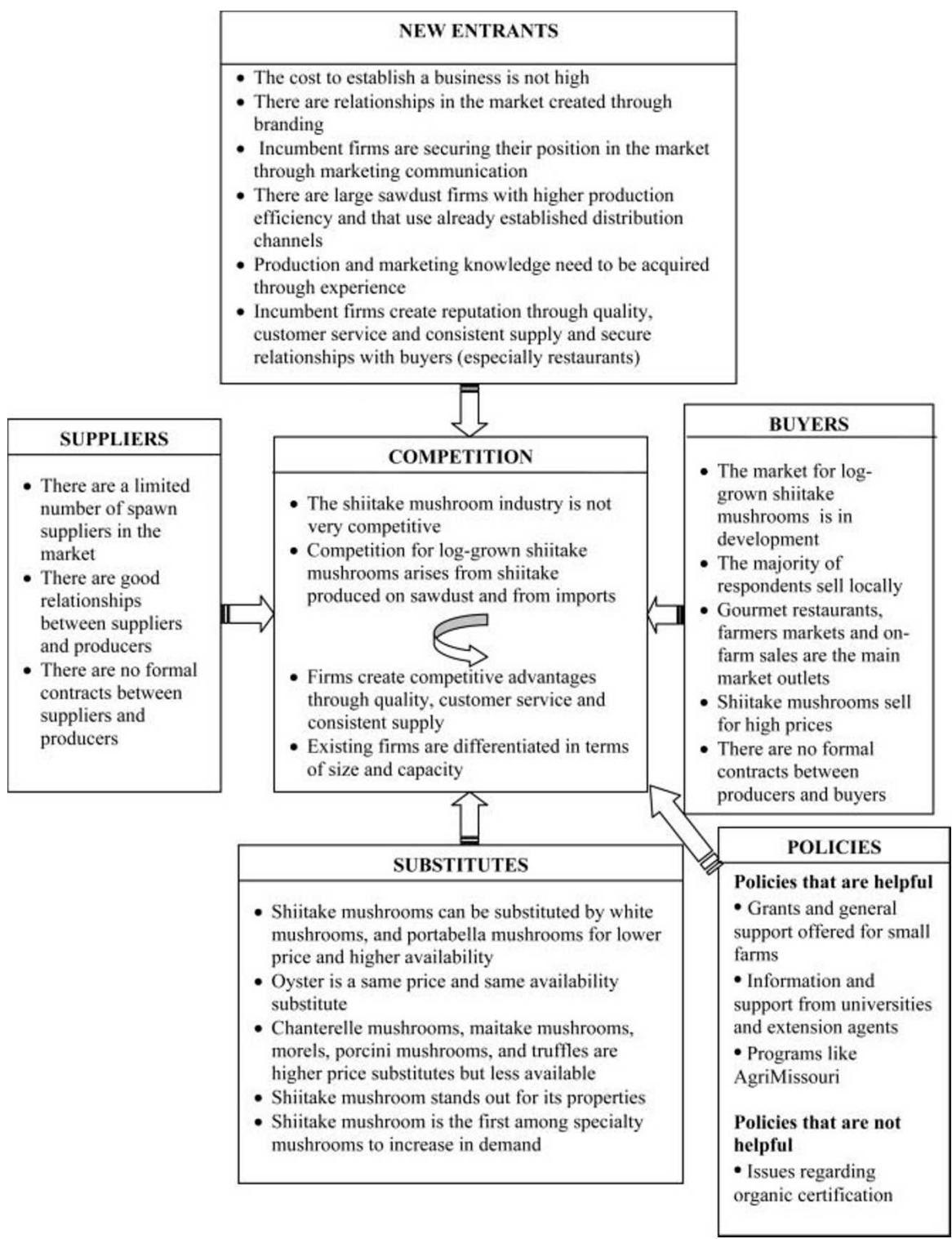

Fig. 6. Representation of the influence of the Porter's Five Forces (Porter, 1980) on the shiitake mushroom market as resulted from a nationwide survey of the U.S. shiitake mushroom producers $(\mathrm{N}=36)$. companies trying to enter the market (Porter, 1980).

The start-up and growing costs for a 4-year production cycle, including the cost of logs, was estimated in a publication of the University of Kentucky Extension (Szymanski et al., 2003 ) at about $\$ 3000$. After establishment, the biggest problem is the availability of affordable and dependable labor

Strong relationships and brand identity can create loyalty to the products of incumbent firms, whereas time and money are required for a new firm to create its own relationships and a competing brand. Respondents that sell value-added products were more likely to create a brand than those who sell fresh shiitake mushrooms to restaurants or farmers markets. Incumbent shiitake mushroom producers secure their position in the market through marketing communication (i.e., advertising and publicity). Consumers are often unfamiliar with niche agroforestry products (i.e., log-grown shiitake mushrooms), therefore, the more information provided about the products benefits, the more likely people are to try the product. Communicating "health benefits," "freshness," "local," or "small-scale production method" can be an important promotion strategy (Darby, 2006).

In terms of economies of scale, large firms that grow on sawdust and produce mushrooms with higher production efficiency than small firms (i.e., synthetic logs may produce three to four times as many mushrooms as natural logs in one-tenth of the time; Royse, 2001) can create barriers to entry. Many large white button mushroom firms diversified their production to include different kinds of specialty mushrooms, including shiitake mushrooms. These firms already have production facilities and distribution channels in place, making the production and marketing process much easier, creating an advantage over small firms (Chen, n.d.).

Another advantage for existing firms is the knowledge about production and marketing acquired through practical experience (i.e., the learning curve) because mushroom cultivation demands a level of care and attention to detail higher than ordinary gardening and agriculture (Chen, n.d.). 
B ARgAINING POWER OF SUPPLIERS. Supplier bargaining power is high when the market is dominated by a few large suppliers rather than many fragmented sources of supply, when there are no substitutes for the particular input, and when switching costs from one supplier to another are high (Porter, 1980).

The limited number of major spawn suppliers in the market could be a sign of strong supplier bargaining power, but the fact that suppliers and producers maintain good relationships, coupled with the existence of alternate suppliers, reduces supplier bargaining power. To further decrease the bargaining power of spawn producers, shiitake mushroom growers could produce their own spawn, increase their knowledge about different suppliers' offers, and find alternate suppliers.

BARGAINING POWER OF BUYERS. The bargaining power of buyers is high when they buy large volumes, when there is a concentration of buyers, when the product is undifferentiated and can be replaced by substitutes, when customers are price sensitive, and when customers could produce the product themselves (Porter, 1980).

The market for log-grown shiitake mushrooms is still developing. Shiitake mushrooms' selling points that differentiate them from substitutes include their aromatic flavor, they are rich in proteins, vitamins and minerals, and low in calories and fat, and they have other health benefits (Mattila et al., 2000). Market prices for fresh shiitake mushrooms vary by season and market outlet. According to National Agricultural Statistics Service (USDA, 2006), the price received by shiitake mushroom growers in 2006 (average price producers receive at point of first sale) was $\$ 3.24 / \mathrm{lb}$, similar to 2005 $(\$ 3.23 / \mathrm{lb})$. The USDA Agricultural Marketing Service provides daily reports about wholesale prices at different terminal markets. According to the information provided (USDA, $2007 \mathrm{~b}$ ), average wholesale prices at the main terminal markets varied in 2006 between $\$ 4.00 / 1$ b and $\$ 5.50 /$ lb (Table 3 ). For the survey respondents, wholesale prices varied between $\$ 5 / \mathrm{lb}$ and $\$ 7 / \mathrm{lb}$, and the highest prices were obtained when selling to restaurants, online, or at the farm gate.

Some publications indicate that prices should be higher for log-grown shiitake mushrooms because shiitake mushrooms grown on logs are meatier, tastier, have a longer shelf life, and have better medicinal and nutritional properties (Bierly, 2001; Mycosource, n.d.). Anecdotal information from a U.S. shiitake mushroom grower indicates that Japanese consumers pay up to 10 times more for log-grown shiitake mushrooms compared with sawdust-grown mushrooms (Lost Creek Shiitake Mushroom Farm, 2008). U.S. consumers at the retail level apparently do not know or appreciate the difference and pay the same price for both categories (Fig. 4).

According to survey results, the bargaining power of buyers is not excessive. To further reduce the force's impact, producers can create relationships with buyers and sustain these relationships by providing good quality mushrooms, maintaining quality through the supply channel, being dependable, communicating, and educating the buyers. To maintain a steady supply and to help market the mushrooms, producers can create partnerships with other producers (i.e., broker for other growers or create marketing cooperatives). The limitation of the study in analyzing this force is that surveys were not directed toward large-scale grocers (e.g., Whole Foods Market); therefore, our conclusions are restricted mainly to the opinion of producers.

ThrEAT OF SUBSTITUTE PRODUCTS. A threat of substitutes exists if there are alternative products with lower prices, better quality, nutritional benefits, and availability that can be used for the same purposes (Porter, 1980).

There are substitutes for shiitake mushrooms, but this type of mushroom stands out for its flavor, nutritional properties, and availability, and is experiencing the most rapid increase in demand among specialty mushrooms. Shiitake mushrooms are well known for high nutritional value because of their high fiber content and for containing medically functional antitumor and immunomodulating polysaccharides (Beelman et al., 2003). Further capitalizing on the additional properties of log-grown shiitake mushrooms (meatier, richer flavor, better shelf life, and higher nutritional and medicinal value) would encourage consumers to seek out log-grown shiitake mushrooms.

RIVALRY AMONG EXISTING FIRMS. This force describes the intensity of competition between existing businesses in the market. Intense rivalry exists if there are many participants about the same size and capacity in the market or if there are low market growth rates (Porter, 1980).

The shiitake mushroom industry is not considered competitive by the

Table 3. Wholesale prices for shiitake mushrooms at different terminal markets during 2006 (U.S. Department of Agriculture, 2007b).

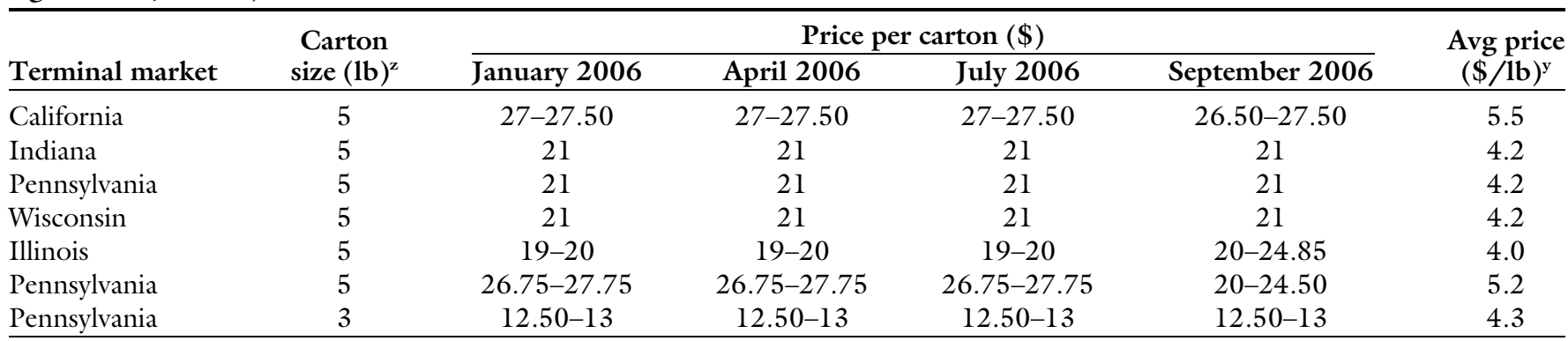

${ }^{\mathrm{z}} \mathrm{l} \mathrm{lb}=0.4536 \mathrm{~kg}$.

${ }^{\mathrm{y}} \$ 1.00 / \mathrm{lb}=\$ 2.2046 / \mathrm{kg}$. 
respondents. However, the opinion about competitiveness is influenced by the size of the firm and the number of firms in a given area. Competition for log-grown shiitake mushrooms arises, especially in wholesale markets, from shiitake mushrooms produced on sawdust (Royse, 2001) or from imports. According to the Agricultural Marketing Research Center (Burden, 2006), Chinese mushroom production and export to the United States has increased yearly over the last two decades and can provide competition to small-scale U.S. growers. To compete, a small-scale start-up producer may wish to develop a niche market for high-quality fresh products or produce a value-added product. High quality standards, excellent service, and consistent supply will help differentiate competitors and create strong relationships, especially with local customers.

Policies that influence the INDUSTRY. Grants and general support offered for small farms and direct marketing were mentioned among the policies that help establish a shiitake mushroom business. Information and support offered by university specialists and extension agents and government program designed to promote Missouri products) were also helpful.

Some respondents mentioned a recent controversy regarding the use of cheese wax and organic certification programs like AgriMissouri (a state

that is affecting their ability to remain organic. However, a petition to add cheese wax to the National List of Allowed Substances was received and is being reviewed by the National Organic Program of the USDA.

\section{Conclusion}

Shiitake mushrooms are grown more as a side business than a fulltime business, especially by growers who focus exclusively on outdoor operations. Indoor production on sawdust generates higher income than outdoor production on logs, but production on logs is more suitable for small-scale operations in an agroforestry setting.

Shiitake mushroom production on logs has many positive aspects. Shiitake mushrooms can provide additional income when using available resources with low capital investment, while increasing the value of the managed woodlot. Log-grown shiitake mushrooms are popular for their taste, nutritional and medicinal properties, and higher quality than sawdust-grown shiitake mushrooms. Trends in demand for shiitake mushrooms at the retail, foodservice channel, and individual consumption levels are increasing and prices are high. Local sales to restaurants, farmers markets, and on-farm outlets are promising (Table 4).

Some notable barriers to success in the shiitake mushroom business

Table 4. Strengths and weaknesses of log-grown shiitake mushroom production summarized from answers to a nationwide survey of U.S. shiitake mushroom producers.

\begin{tabular}{lc}
$\begin{array}{l}\text { Strengths of log-grown } \\
\text { shiitake mushroom production }\end{array}$ & $\begin{array}{c}\text { Weaknesses of log-grown } \\
\text { shiitake mushroom production }\end{array}$ \\
\hline - Popularity for taste, and nutritional & - Hard work and serious commitment \\
and medicinal properties & - l-year time lag to obtain a return \\
- Sustainability & - Seasonal production \\
- Low capital investment & - Dependence on weather \\
- Use of available resource & - Competition from sawdust-grown shiitake \\
- Quality product & mushrooms and imports \\
- Provides additional income & - Issues regarding organic certification \\
- Trend in demand is upward & $\begin{array}{l}\text { Need for strong and direct relationships } \\
\text { in the market }\end{array}$ \\
- Prices are high & The learning curve effect \\
- Most sales are local & \\
- Restaurants, farmers markets, and & \\
$\begin{array}{l}\text { on-farm outlets are the main venues } \\
\text { to market shiitake mushrooms }\end{array}$ & \\
\hline
\end{tabular}

include the following: strenuous work requirements and a need for serious commitment to produce and market shiitake mushrooms; the learning curve effect that requires experience to increase production and marketing efficiency; seasonal production dependent on weather; and the need for strong and direct relationships in the market. Compared with vegetable growing, there is a substantial time lag between investment and a return on investment. There is competition for a new business entering the market from existing log-based producers that have already created relationships with main buyers in the area, from shiitake mushrooms produced on sawdust, and from imports (Table 4).

Respondents increased their return from log-grown shiitake mushrooms by creating indoor facilities to extend production times, by producing value-added products (to use the surplus of fresh shiitake mushrooms and to differentiate from competitors), and by selling mushrooms for other growers to ensure continuity in supply. Additional success can be obtained by capitalizing on the log-grown properties of shiitake mushrooms in the marketing effort (e.g., meatier, richer flavor, better shelf life, and higher nutritional and medicinal value), creating strong relationships with buyers, and acquiring and continuously improving production and marketing skills. Branding and marketing communication also helped strengthen relationships in the market.

The survey provided valuable information about the market. This information will be disseminated to growers, grower associations, and mushroom publications. To help the market grow, grower association, universities, and state and federal agencies must continue production and market research, organize trainings, work with produce buyers to ensure that only quality products are offered for sale, and continue to educate consumers about the nutritional and health benefits of shiitake mushrooms.

\section{Literature cited}

Augostini, N. 2002. Specialty mushrooms survey. 8 Feb. 2008. <http://www. 
cals.ncsu.edu/specialty_crops/marketing/ MushroomSurvey.pdf $>$.

Beelman, R.B., D.J. Royse, and N. Chikimmah. 2003. Bioactive components in button mushroom Agaricus bisporus (J.Lge) Imbach (Agaricomycetideae) of nutritional, medicinal and biological importance. Intl. J. Medicinal Mushrooms 5:321-337.

Beetz, A. and M. Kustudia. 2004. Mushroom cultivation and marketing. 8 Feb. 2008. <http://www.attra.org/attrapub/PDF/mushroom.pdf>.

Bierly, P. 2001. The mushroom market. 8 July 2007. <http://www.lightstone.org/ $\mathrm{dev} /$ farmprograms/shiitakemushroom project/index.html>.

Burden, D. 2006. Mushroom profile. 8 Feb. 2008. <http://www.agmrc.org/ agmrc/commodity/specialitycrops / mushrooms/mushroomsprofile.htm $>$.

Chen, $M$ (n.d.). A potential new profit from oak woodlands. Integrated Hardwood Range Management Program (IHRPM), IHRPM Oak Fact Sheets No. 34. 8 Feb. 2008. <http://danr.ucop.edu/ihrmp/ oak34.htm>.

Darby, K., M.T. Batte, S. Ernst, and B. Roe. 2006. Willingness to pay for locally produced foods: A customer intercept study of direct market and grocery store shoppers. 3 Jan. 2008. <http://wwwagecon.ag.ohio-state.edu/programs/ VanBuren/pdf/AAEA\%20Selected $\% 20$ Paper-156532.pdf>.

Degner, R.L. and M.B. Williams. 1991. Marketing alternatives for north Florida shiitake mushroom producers. FAMRC Ind. Rpt. 91-1. Florida Agr. Mkt. Res. Ctr. Inst. Food Agr. Sci., Univ. of Florida, Gainesville.

Dillman, D.A. 2000. Mail and internet surveys. The tailored survey method. Wiley, New York.
Gold, M.A., M.M. Cernusca, and L.D. Godsey. 2006. Competitive market analysis: Chestnut producers. HortTechnology 16(2):360-369.

Gold, M.A., L.D. Godsey, and M.M. Cernusca. 2005. Competitive market analysis of eastern red cedar. Forest Products J. 55(12):58-65.

Lost Creek Shiitake Mushroom Farm. 2008. Facts and nutrition. 8 Feb. 2008. $<$ http://shiitakemushroomlog.com/ facts\&nutrition.html>.

Lucier, G., J. Allhouse, and B.-H. Lin. 2003. Factors affecting U.S. mushroom consumption. 8 Feb. 2008 . <www.ers.usda.gov/publications/VGS/ mar03/vgs29501/vgs29501.pdf $>$.

Mattila, P., K. Suonpaa, and V. Piironen. 2000. Functional properties of edible mushrooms. Nutrition 16(7-8):694696.

Mycosource Inc. (n.d.). Natural log shiitake mushroom production, processing and marketing. 8 Feb. 2008. <http://www.mycosource.com/shiilogs. htm>.

Onianwa, O., B. Wesson, and G. Wheelock. 2000. An analysis of the retail-level market potential for locally grown shiitake mushrooms in north Alabama. J. Food Distribution Res. 31(1):159-168.

Patterson, P.M. 2003. A mushroom forecasting model: Review and evaluation. 2 Oct. 2007. <http://mushroomcouncil. org/docs/Mushroom+Outlook+patterson+ forecast.pdf>.

Pickford, J.C. 1989. The Ohio shiitake mushrooms market study findings. Shiitake mushrooms. Proc. Natl. Symp. Trade Show, 3-5 May 1989, Ctr. Alternative Plant Animal Products, College Natural Resources, Univ. of Minnesota, St. Paul. p. 151-161.
Porter, M.E. 1980. Competitive strategy: Techniques for analyzing industries and competitors. Free Press, New York.

Royse, D.J. 2001. Cultivation of shiitake on natural and synthetic logs. 8 Feb. 2008. <http://pubs.cas.psu.edu/Free Pubs/pdfs/ul203.pdf $>$.

Szymanski, M., D. Hill, and T. Woods. 2003. Potential profits from a small-scale shiitake enterprise. Kentucky shiitake production workbook. Univ. of Kentucky, College Agr., Coop. Ext. Serv. FOR-88. 8 July 2007. <http://www.ca.uky.edu/ $\mathrm{agc} / \mathrm{pubs} /$ for/for88/for88.pdf>.

Technomic Inc. 2005. Assessment of fresh mushrooms in the foodservice channel. 8 July 2007. <http://www. mushroomcouncil.org/docs/2005_04$29+$ Assess + of + Fresh + Mush + in + FS + Channel.pdf $>$.

University of Missouri Center for Agroestry. 2008. Shiitake mushroom market research: Producer survey. 11 Feb. 2008. <http://www.centerforagroforestry.org/ pubs/index.asp $>$.

U.S. Department of Agriculture. 2004. Mushrooms. 2 Feb. 2008. <http:// usda.mannlib.cornell.edu/usda/nass / Mush//2000s/2004/Mush-08-162004.pdf>.

U.S. Department of Agriculture. 2006. Mushrooms. 8 July 2007. <http://usda. mannlib.cornell.edu/usda/nass / Mush//2000s/2006/Mush-08-162006.pdf>.

U.S. Department of Agriculture. 2007a. Vegetables and melons outlook. 6 Feb. 2008. <www.ers.usda.gov/publications/ vgs/tables/percap.pdf>

U.S. Department of Agriculture. 2007b. Terminal market report. Fruit and vegetable market news. 8 Feb. 2008. <http:// marketnews.usda.gov/portal/fv $>$. 